\title{
Dinâmicas de urbanização na hiperperiferia da metrópole de São Paulo: análise dos processos de expansão urbana e das situações de vulnerabilidade socioambiental em escala intraurbana ${ }^{*}$
}

\author{
Humberto Prates da Fonseca Alves ${ }^{\star \star}$ \\ Claudia Durand Alves ${ }^{* *}$ \\ Madalena Niero Pereira**** \\ Antonio Miguel Vieira Monteiro*****
}

\begin{abstract}
O objetivo do trabalho é fazer uma análise, em escala intraurbana, das interrelações entre os processos de expansão urbana e as situações de vulnerabilidade socioambiental, em uma região hiperperiférica da metrópole de São Paulo, no período recente (2000 a 2006). A referida região abrange o distrito de Cidade Tiradentes e seu entorno, no extremo leste do município de São Paulo. A metodologia geral do estudo envolve o mapeamento do uso do solo e das áreas de expansão urbana, por meio de imagens de satélite, bem como identificação e caracterização de situações (áreas) de vulnerabilidade socioambiental, pela construção e análise de indicadores socioambientais ao nível dos setores censitários do Censo 2000 do IBGE, integrando dados socioeconômicos, demográficos e ambientais. Os resultados revelam uma expressiva associação entre os processos de expansão urbana e crescimento de assentamentos precários e as situações de vulnerabilidade socioambiental, na região hiperperiférica de Cidade Tiradentes e entorno. Além disso, observa-se existência de grandes sobreposições entre vulnerabilidades sociais e ambientais, com forte concentração de problemas e riscos sociais e ambientais em determinadas áreas, como é o caso dos setores censitários de alta vulnerabilidade socioambiental da região de Cidade Tiradentes e entorno. Estas áreas apresentam altos níveis de irregularidade no uso do solo, com forte presença de assentamentos precários como favelas e loteamentos irregulares, além de condições socioeconômicas extremamente desfavoráveis, com baixíssimos níveis de renda, escolaridade e saneamento.
\end{abstract}

Palavras-chave: Expansão urbana. Vulnerabilidade socioambiental. Hiperperiferia. Metrópole de São Paulo. Indicadores socioambientais. Geoprocessamento. Sensoriamento remoto.

\footnotetext{
* O presente trabalho é resultado de um projeto desenvolvido em parceria entre o Centro de Estudos da Metrópole (CEM-Cebrap) e a Coordenadoria de Observação da Terra do Instituto Nacional de Pesquisas Espaciais (OBT-Inpe), para o desenvolvimento de metodologias para análise e monitoramento dos processos de expansão urbana na Região Metropolitana de São Paulo.

** Professor do curso de Ciências Sociais da Universidade Federal de São Paulo (Unifesp), campus Guarulhos. Economista e doutor em Ciências Sociais pela Universidade Estadual de Campinas (Unicamp).

*** Pesquisadora da Divisão de Sensoriamento Remoto do Instituto Nacional de Pesquisas Espaciais (DSR-Inpe). Mestranda em Sensoriamento Remoto pelo Inpe. Arquiteta e urbanista pela Universidade de São Paulo (USP)

${ }_{* * * *}$ Pesquisadora da Divisão de Sensoriamento Remoto do Instituto Nacional de Pesquisas Espaciais (DSR-Inpe). Mestre em Sensoriamento Remoto pelo Inpe. Geógrafa pela Universidade de São Paulo (USP).

****** Pesquisador sênior da Divisão de Processamento de Imagens do Instituto Nacional de Pesquisas Espaciais (DPIInpe). Doutor em Engenharia Eletrônica pela Universidade de Sussex na Inglaterra. Engenheiro elétrico pela Universidade Federal do Espírito Santo (Ufes).
} 


\section{Introdução}

A segunda metade do século XX marcou a aceleração do processo de urbanização no Brasil, em particular no Estado de São Paulo, acarretando, principalmente, a formação de regiões metropolitanas, a verticalização e o adensamento das áreas já urbanizadas e a expansão urbana para as áreas periféricas (REIS; TANAKA, 2007; MEYER et al., 2004). No Estado de São Paulo, estes processos assumiram grandes proporções, fazendo com que a população urbana chegasse a quase 40 milhões de pessoas em 2010 (cerca de 95\% do total estadual). Grande parte desta população urbana vive em regiões de caráter metropolitano, sendo a principal delas a Região Metropolitana de São Paulo, que abrange 39 municípios e já abriga quase 20 milhões de pessoas em 2010.1

No presente trabalho, serão estudadas algumas dimensões sociais e ambientais das dinâmicas de urbanização que estão ocorrendo em uma região hiperperiférica da metrópole de São Paulo, no período recente (2000 a 2006). Mais especificamente, o foco recairá nos processos de expansão urbana (periferização e periurbanização) e nas situações de vulnerabilidade socioambiental, procurando analisar as inter-relações entre estes dois fenômenos em escala intraurbana.

Os processos de expansão urbana, periferização e periurbanização, que se desenvolvem na metrópole de São Paulo, são muito diversos, envolvendo a dispersão espacial tanto de grupos de baixa renda (exemplificados pela autoconstrução e por loteamentos irregulares e favelas), quanto de grupos de média e alta renda (como os condomínios fechados). Estas dinâmicas de ocupação das áreas periféricas e periurbanas têm fortes implicações sociais e ambientais. Entre os impactos socioambientais deste processo de periferização, está a ampliação das jornadas entre o centro e as áre- as periféricas, com consequente aumento do trânsito e da poluição do ar. A expansão destas áreas também implica ausência de saneamento básico, principalmente rede de esgoto, e poluição de rios e córregos, além de um forte processo de desmatamento e degradação ambiental (TORRES; ALVES; OLIVEIRA, 2007a).

Já as situações de vulnerabilidade socioambiental podem ser definidas como a sobreposição ou cumulatividade de problemas e riscos sociais e ambientais, que se concentram em determinadas áreas, espalhadas por toda a metrópole. Esta sobreposição (ou coexistência espacial) faz com que situações de pobreza e vulnerabilidade social, presentes em muitas áreas periféricas e periurbanas, sejam agravadas por exposição a riscos e degradação ambiental, tais como enchentes, deslizamentos de terra, poluição, contato com doenças de veiculação hídrica, etc. Portanto, acreditamos que o conceito de vulnerabilidade socioambiental pode captar e traduzir os fenômenos de sobreposição espacial e interação entre problemas e riscos sociais e ambientais, sendo adequado para analisar o crescente entrelaçamento entre as dimensões sociais e ambientais da urbanização (ALVES, 2006; ALVES; TORRES, 2006).

Assim, o objetivo geral deste trabalho é fazer uma análise, em escala intraurbana, das inter-relações entre os processos de expansão urbana e as situações de vulnerabilidade socioambiental, em uma região hiperperiférica da metrópole de São Paulo, no período recente (2000 a 2006). ${ }^{2}$ Desse modo, serão analisadas as associações entre estes dois fenômenos, particularmente a forma como os processos de expansão urbana e crescimento das áreas periféricas e periurbanas podem gerar novas situações de vulnerabilidade socioambiental, ao promoverem a presença de população de baixa renda em áreas sem infraestrutura e serviços urbanos e com exposição a riscos e degradação ambiental. É o caso,

\footnotetext{
1 Dados da Fundação Sistema Estadual de Análise de Dados - Seade. Disponível em: <www.seade.gov.br>. Acesso em: 02/02/2010.

2 A referida região abrange o distrito de Cidade Tiradentes e entorno, no extremo leste de São Paulo.
} 
por exemplo, do surgimento e expansão de loteamentos irregulares e favelas em áreas de risco e naquelas protegidas por legislação ambiental, nas periferias e áreas periurbanas dos diversos municípios da Região Metropolitana de São Paulo.

Para atingir o objetivo proposto no trabalho, a metodologia geral do estudo envolve o mapeamento do uso do solo e das áreas de expansão urbana, por meio de imagens de satélite, e a identificação e caracterização de situações (áreas) de vulnerabilidade socioambiental, com a construção e análise de indicadores socioambientais ao nível dos setores censitários do Censo 2000 do IBGE, integrando dados socioeconômicos, demográficos e ambientais. ${ }^{3}$

Portanto, este artigo traz contribuições metodológicas, empíricas e analíticas bastante relevantes e atuais para os estudos de população, em sua interface com os estudos urbanos e ambientais. ${ }^{4}$

\section{Breve revisão da literatura}

Além da breve revisão de uma literatura que discute os temas vulnerabilidade socioambiental e expansão urbana, apresenta-se uma rápida discussão sobre aplicações de geoprocessamento e sensoriamento remoto para áreas urbanas e metropolitanas.

Uma parte significativa da literatura sobre a questão urbana no Brasil mostra que a expansão urbana para as áreas periféricas está relacionada à procura por habitação em áreas com baixo preço da terra, o que provoca aumento das ocupações precárias, como favelas e loteamentos irregulares, em áreas sem infraestrutura e expostas a risco e degradação ambiental (BONDUKI; ROLNIK, 1982; SMOLKA, 1993; MARICATO, 1996).
Assim, esta dinâmica de urbanização nas regiões periféricas, através da ocupação ilegal e predatória de terra urbana, faz com que grande parte das áreas urbanas de risco e proteção ambiental, tais como as margens dos cursos d'água, esteja ameaçada pelas ocupações precárias de uso habitacional de baixa renda, por absoluta falta de alternativas habitacionais, seja via mercado privado, seja via políticas públicas sociais (MARICATO, 2003).

Portanto, há uma tendência de os grupos de mais baixa renda residirem em áreas com más condições urbanísticas e sanitárias e em situações de risco e degradação ambiental, tais como terrenos próximos de cursos d'água e de lixões ou com alta declividade. A explicação mais geral é a de que estas constituem as únicas áreas acessíveis à população de mais baixa renda, seja porque são públicas e/ou de preservação (invadidas), seja porque são muito desvalorizadas no mercado de terras, devido às características de risco e à falta de infraestrutura urbana (ALVES, 2007). ${ }^{5}$

De fato, o nível dos problemas sociais e ambientais de determinadas áreas é impressionante, superpondo, em termos espaciais (e sociais), os piores indicadores socioeconômicos com riscos de enchentes e deslizamentos de terra, um ambiente intensamente poluído e serviços públicos extremamente ineficientes. Assim, em alguns espaços da periferia, verifica-se intensa concentração de indicadores negativos, que sugerem a presença de "pontos críticos" de vulnerabilidade social (e ambiental), revelando a existência de uma espécie de periferia da periferia (TORRES; MARQUES, 2001).

Na metrópole de São Paulo, o expressivo crescimento demográfico e a expan-

\footnotetext{
${ }^{3}$ Nesse sentido, a identificação e caracterização de alguns padrões específicos de sobreposição espacial de situações de risco e vulnerabilidade sociais e ambientais, existentes na metrópole paulistana, requerem o desenvolvimento de análises muito detalhadas, tais como aquelas possibilitadas por sistemas de informação geográfica e métodos de geoprocessamento, utilizando unidades espaciais de análise extremamente desagregadas, como os setores censitários.

4 No âmbito dos estudos de população, o presente artigo pretende contribuir e dialogar, principalmente, com as áreas de população e meio ambiente e distribuição espacial da população, particularmente com o Grupo de Trabalho População, Espaço e Ambiente, da Associação Brasileira de Estudos Populacionais (Abep).

5 Para Jacobi (1995), há uma relação direta entre exposição a riscos ambientais e precariedade de acesso a serviços públicos. A própria ausência de infraestrutura urbana (água, esgoto, coleta de lixo, canalização de córregos, etc.) expõe as populações residentes nestas áreas a riscos ambientais, como as doenças de veiculação hídrica.
} 
são horizontal das áreas periféricas mais distantes, também denominadas hiperperiferia ou fronteira urbana, têm contribuído para o aumento da heterogeneidade das periferias e para o crescimento da pobreza e vulnerabilidade social e ambiental. A porção da periferia que Torres (2005) classifica como "fronteira urbana" refere-se a um tipo particular de periferia, com altas taxas de crescimento demográfico e substancial migração e precariedade no acesso a serviços públicos, particularmente saneamento. $\mathrm{Ou}$ seja, as fronteiras urbanas são regiões que apresentam infraestrutura precária e em construção, sendo objeto de importantes conflitos sobre a posse da terra urbana (loteamentos clandestinos, favelas). O Estado, em geral, está pouco presente, seja regulando o uso da terra, seja por meio da oferta de serviços públicos. Estes elementos revelam o elevado grau de vulnerabilidade social (e ambiental) destas áreas hiperperiféricas e de fronteira urbana (TORRES; ALVES; OLIVEIRA, 2007a). ${ }^{6}$

$\mathrm{Na}$ verdade, desde a década de 1970, tem havido um forte processo de periferizacão, com incorporação de uma vasta área à mancha urbana da metrópole, muitas vezes pela invasão de terras por loteamentos clandestinos e favelas (MARCONDES, 1999). Nas três últimas décadas, os dois grandes eixos de expansão da cidade de São Paulo foram as regiões leste e sul, sendo que esta última, inserida na área de proteção a mananciais, tem apresentado forte ritmo de crescimento, que se intensificou nos últimos anos. Mais recentemente, vem ocorrendo forte expansão na direção da região norte do município, que está localizada nas encostas da Serra da Cantareira, com muitas áreas com altas declividades (MEYER et al., 2004). ${ }^{7}$

Nas últimas décadas, também tem ocorrido um forte processo de expansão e periferização das favelas da Região Metropolitana de São Paulo, particularmente no município de São Paulo, geralmente ocupando áreas públicas que, muitas vezes, localizam-se em fundos de vale e beiras de córregos, com risco de enchentes, ou em encostas com declividades acentuadas, com alta propensão à erosão (TASCHNER, 2000).

Cabe destacar que estes grandes processos de transformação por que têm passado as áreas periféricas da metrópole de São Paulo explicitam um crescente entrelaçamento e sobreposição entre problemas socioeconômicos e ambientais, constituindo um desafio para as políticas públicas que, na maioria das vezes, são compartimentalizadas segundo áreas de intervenção setorial. Assim, o grande número de situações de sobreposição de péssimas condições sociais e sanitárias a riscos e conflitos ambientais torna necessárias abordagens que contemplem as relações e interações entre as dimensões sociais e ambientais da urbanização (ALVES, 2006; ALVES; TORRES, 2006).

Nesse sentido, um conceito viável para analisar estas relações é o de vulnerabilidade socioambiental, que pode ser definido como a coexistência, cumulatividade ou sobreposição espacial de situações de pobreza/ privação social e de situações de exposição a risco e/ou degradação ambiental. Assim, é justamente a combinação dessas duas dimensões - social e ambiental - que está sendo considerada uma situação de vulnerabilidade socioambiental (ALVES, 2006). ${ }^{8}$

\footnotetext{
6 Os termos hiperperiferia e fronteira urbana têm sido usados para caracterizar as regiões da extremidade da periferia metropolitana de São Paulo, com ausência de serviços e infraestrutura urbana e alta concentração de pobreza e de assentamentos precários. Ver Torres e Marques (2001), Torres (2005) e Torres, Alves e Oliveira (2007a e b).

7 Portanto, a lei de proteção aos mananciais não conseguiu restringir a ocupação urbana das áreas norte, sul, sudeste e sudoeste da RMSP, onde estão localizados os mananciais hídricos e os remanescentes florestais da metrópole. Ao contrário, o que ocorreu foi uma urbanização periférica e descontínua, com degradação dos recursos hídricos e altas taxas de desmatamento nestas áreas (OLIVEIRA; ALVES, 2007).

8 É importante destacar que o conceito de vulnerabilidade socioambiental não trata simplesmente da exposição aos riscos ambientais, mas também da capacidade das pessoas de lidarem com estes riscos. Assim, a vulnerabilidade socioambiental pode ser pensada em termos de pelo menos dois aspectos (ou dimensões): grau de exposição e suscetibilidade ao risco ambiental. Nesta perspectiva, as pessoas ou grupos sociais mais vulneráveis seriam aqueles mais expostos e mais sensíveis a situações de risco e degradação ambiental. Nisto residem a importância e a inseparabilidade das dimensões social e ambiental da vulnerabilidade (DE SHERBININ et al., 2007).
} 
No Brasil, o Grupo de Trabalho População, Espaço e Ambiente, da Associação Brasileira de Estudos Populacionais (Abep), tem tido papel fundamental no avanço conceitual e metodológico, no contexto da demografia, nos estudos sobre risco e vulnerabilidade. Um dos conceitos centrais abordados pelos pesquisadores deste grupo foi o de populações em situação de risco (MARANDOLA; HOGAN, 2005).

Em um dos livros publicados por este grupo, Torres (2000) discute teoricamente o conceito de risco ambiental, debatendo sobre os problemas e as dificuldades para sua operacionalização. Para o autor, um dos aspectos mais relevantes diz respeito à questão da cumulatividade de riscos de diferentes origens. Nesse sentido, as áreas de risco ambiental (próximas de lixões, sujeitas a inundações e desmoronamentos), muitas vezes, são as únicas acessíveis às populações de mais baixa renda, que acabam construindo nesses locais domicílios em condições precárias, além de enfrentarem outros problemas sanitários e nutricionais.

Para finalizar esta breve revisão da literatura, apresenta-se, a seguir, uma rápida discussão sobre aplicações de geoprocessamento e sensoriamento remoto para áreas urbanas e metropolitanas.

O monitoramento da expansão urbana em regiões metropolitanas torna-se difícil e oneroso se realizado com técnicas convencionais de obtenção de dados, como levantamentos de campo e aerofotogramétricos tradicionais. Em países com dimensões continentais e escassez de recursos para atualização de dados cartográficos fundamentais para estudos que envolvem a espacialização das informações, como no caso do Brasil, o uso de imagens de satélite poderá fornecer informações importantes de fenômenos que se diferenciam pelo seu dinamismo, como é o caso da expansão das áreas urbanas e periurbanas, principalmente em regiões metropolitanas. Assim, uma fonte confiável e atualizável de dados para estudos urbanos, alimentação de modelos urbanos e validação dos mesmos pode ser fornecida por Sensoriamento Remoto (PENG et al., 2007).
Até o começo dos anos 2000, a maioria dos trabalhos de Sensoriamento Remoto era focada em levantamento de recursos naturais e pouco desenvolvida para estudos urbanos. A aplicação da tecnologia para áreas urbanas, entretanto, se intensificou com $\mathrm{o}$ avanço das imagens de alta resolução. $\mathrm{O}$ progresso tecnológico e o desenvolvimento de novos sensores têm resultado em considerável melhoria da resolução espacial, radiométrica e espectral dos dados. Dessa forma, surgem novas possibilidades de uso de imagens orbitais para estudos urbanos mais detalhados em escalas intraurbana e local (BLASCHKE; KUX, 2005).

Por meio de Sistemas de Informação Geográfica (SIG), os dados retirados das imagens de satélite, a um baixo custo e em curto espaço de tempo, poderão ser integrados a informações obtidas por censos demográficos, pesquisas institucionais e dados de cadastros das prefeituras. $O$ uso de imagens e SIG permite avaliar não apenas os impactos ambientais causados pela urbanização espontânea, mas também os riscos aos quais se submetem as populações por se localizarem em áreas ecologicamente frágeis, como planícies de inundação e áreas de encosta (ALMEIDA et al., 2007).

\section{Breve contextualização da região de estudo - o distrito de Cidade Tiradentes e áreas contíguas}

Na realização do presente trabalho, foi definida como região de estudo uma porção do extremo leste do município de São Paulo, que inclui o distrito de Cidade de Tiradentes e algumas áreas contíguas a ele (Mapa 1).

A região de estudo é representativa dos processos de periferização e crescimento de áreas periurbanas na Região Metropolitana de São Paulo, marcados pela presença de grupos populacionais de baixa renda em áreas sem infraestrutura urbana e expostos a risco e degradação ambiental. Grande parte da região é classificada por estudos anteriores como área de alta vulnerabilidade social (CEM-CEBRAP; SAS-PMSP, 2004).

A expansão de assentamentos precários e informais, como loteamentos irregu- 
MAPA 1

Região de estudo

Distrito de Cidade Tiradentes e áreas no seu entorno

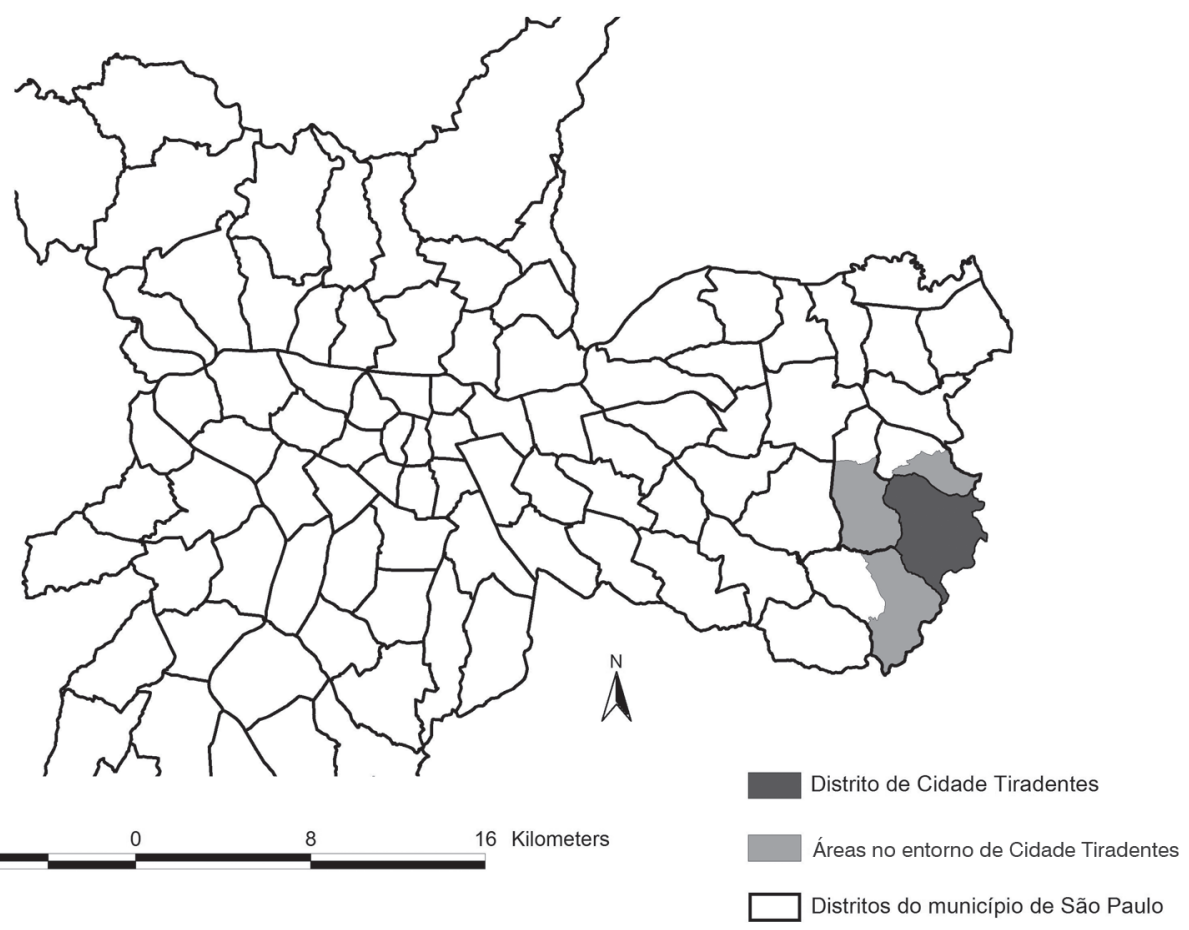

Fonte: IBGE. Malha digital dos distritos do município de São Paulo.

lares e favelas, nessa região, é um aspecto importante para sua seleção como área a ser estudada. Além disso, grande parte da expansão destes tipos de assentamento se deu em áreas de risco ambiental, tais como margens de rios e córregos e localidades de altas declividades, sujeitas a enchentes e deslizamentos, respectivamente. Assim, é uma área que necessita de estudos que forneçam subsídios para o planejamento de políticas públicas sociais e ambientais, no que se refere a habitação, saneamento e uso do solo.

Cidade Tiradentes foi planejada como um grande conjunto periférico tipo "bairrodormitório", com a finalidade de realocar população sem moradia de outros bairros do município de São Paulo e diminuir o déficit habitacional, passando a abrigar enormes contingentes de famílias, que aguardavam na "fila" da casa própria de companhias habitacionais. Esse distrito é considerado, atualmente, o maior complexo de conjuntos habitacionais da América Latina, com cerca de 40 mil unidades habitacionais, a maioria construída na década de 1980 pela Companhia Metropolitana de Habitação de São Paulo (Cohab), pela Companhia de Desenvolvimento Habitacional e Urbano do Estado de São Paulo (CDHU) e por grandes empreiteiras. ${ }^{9}$

Além das questões habitacionais mencionadas anteriormente, a distância do centro de São Paulo e a ausência de postos de trabalho estão entre os principais problemas enfrentados pela população residente em Cidade Tiradentes, que registra um desgastante deslocamento diário de milhares

\footnotetext{
${ }^{9}$ Dados da Prefeitura de São Paulo. Disponível em: <www.prefeitura.sp.gov.br>. Acesso em: 02/02/2010.
} 
de pessoas em direção às regiões centrais, o qual chega a demorar de quatro a cinco horas por dia no percurso casa-trabalhocasa, por meio de ônibus, trem, metrô e van (ALMEIDA et al., 2008).

Com relação às características demográficas e socioeconômicas, o distrito de Cidade Tiradentes possui 191 mil habitantes (ano 2000) e apresenta níveis bastante baixos de renda e escolaridade, além de infraestrutura e serviços urbanos muito precários, correspondendo a um padrão típico de região hiperperiférica da metrópole de São Paulo. ${ }^{10}$ Porém, destaca-se que a região não é homogênea, abrangendo desde áreas formalizadas e legalizadas, como os conjuntos habitacionais, até áreas bastante precárias e informais, como as ocupações, favelas e loteamentos irregulares.

\section{Metodologia}

Para atingir o objetivo proposto no trabalho, que é analisar as inter-relações entre os processos de expansão urbana e as situações de vulnerabilidade socioambiental, a metodologia geral do estudo envolveu o mapeamento do uso do solo e das áreas de expansão urbana, bem como a identificação e caracterização de situações (áreas) de vulnerabilidade socioambiental. Assim, a metodologia do trabalho foi desenvolvida em duas partes: classificação de imagens de satélite, para identificar as classes de uso e cobertura do solo e os processos de expansão urbana, no período 2000-2006; e construção e análise de indicadores sociais e ambientais, ao nível dos setores censitários do Censo 2000 do IBGE, de maneira a operacionalizar o conceito de vulnerabilidade socioambiental. A seguir, descreve-se cada uma destas partes da metodologia.
Inicialmente, foram mapeadas e caracterizadas as classes de uso e cobertura do solo e as áreas de expansão urbana, por meio da classificação e análise multitemporal de duas imagens de satélite de alta resolução espacial (IKONOS) de 2000 e 2006, abrangendo a região do distrito de Cidade Tiradentes e entorno. Com isso, visou-se verificar se houve aumento e mudanças nos diferentes tipos de uso do solo urbano, especialmente de assentamentos precários, como favelas e loteamentos irregulares. ${ }^{11}$

As classificações foram feitas de forma manual, por interpretação visual e edição digital diretamente na tela do computador. A definição das classes que comporiam a legenda de uso e cobertura do solo para a área de estudo levou em consideração os objetivos do trabalho e algumas legendas já existentes. As legendas utilizadas como referência foram o sistema desenvolvido por Anderson et al. (1972) e as classes descritas pela Emplasa, no Mapeamento de uso e ocupação do solo da RMSP (EMPLASA, 2003). O Mapa 2 mostra a imagem classificada da região de Cidade Tiradentes para 2006. ${ }^{12}$

Como já mencionado, a segunda parte da metodologia consistiu na operacionalização do conceito de vulnerabilidade socioambiental, por meio da construção e análise de indicadores sociais e ambientais. Esta metodologia foi originalmente desenvolvida para outro estudo sobre vulnerabilidade socioambiental no município de São Paulo e está descrita em detalhes em Alves (2006).

Para se chegar ao conceito de vulnerabilidade socioambiental, primeiramente foi realizada a operacionalização do conceito de vulnerabilidade social, utilizando-se dados do Mapa da vulnerabilidade social da população da cidade de São Paulo (CEMCEBRAP; SAS-PMSP, 2004). A partir deste

\footnotetext{
10 Dados do Censo 2000 do IBGE. Disponível em: <www.sidra.ibge.gov.br>. Acesso em: 02/02/2010.

${ }^{11}$ As duas imagens do satélite IKONOS utilizadas cobrem uma área de aproximadamente $50 \mathrm{~km}^{2}$ e foram adquiridas em 02 de outubro de 2000 e 23 de novembro de 2006 .

12 É importante enfatizar que a malha de setores censitários de 2000 foi georreferenciada às imagens de satélite, a fim de reduzir possíveis distorções entre os dois tipos de dados. Este procedimento de georreferencimento e ajuste dos dados é de fundamental importância, particularmente no caso dos setores censitários, pois, no momento das análises dos dados sociodemográficos em relação aos mapeamentos, faz-se necessário um perfeito ajuste entre os setores censitários e as imagens de satélite, para que não haja dúvida quanto ao pertencimento de uma determinada quadra ou área, definidas na imagem, a um determinado setor censitário.
} 
MAPA 2

Classes de uso e cobertura do solo a partir da classificação de imagem de satélite IKONOS Distrito de Cidade Tiradentes e entorno - 2006

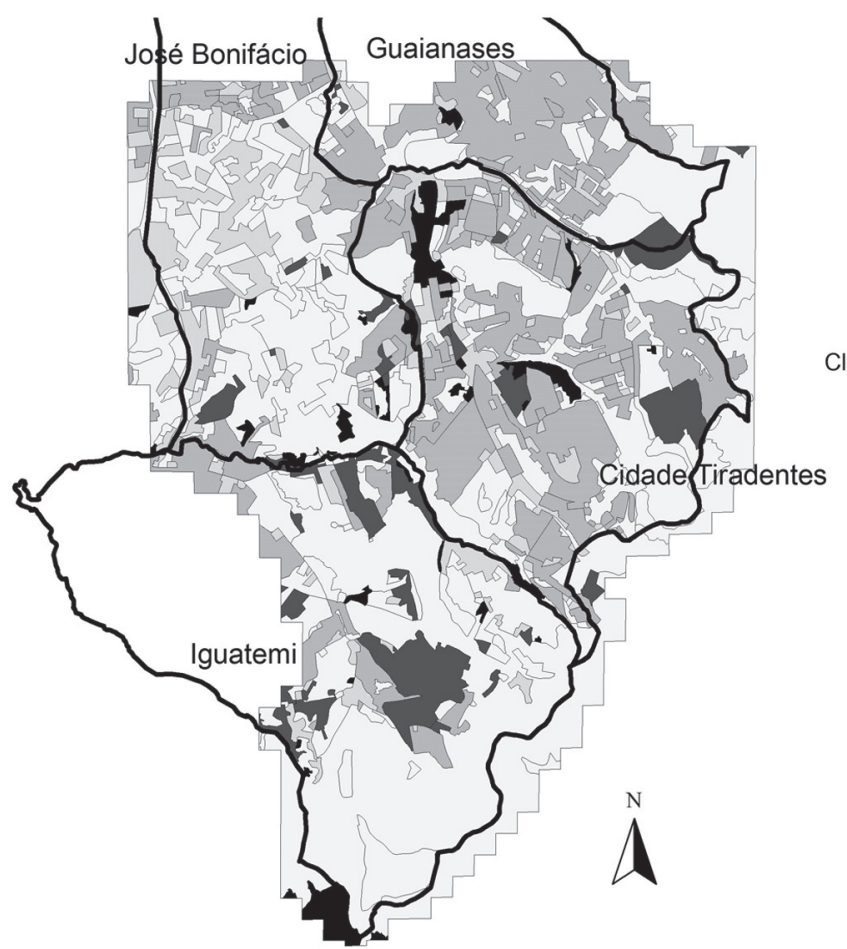

Classes de uso e cobertura do solo em 2006:

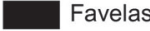

Loteamentos irregulares

Conjuntos habitacionais

Zonas residenciais consolidadas Industrial/comercial/institucional

Áreas não urbanizadas: agricultura, florestas, chácaras, vazios urbanos, lixões, mineração, etc.

$\square$ Distritos da região de estudo

Fonte: Imagem de satélite IKONOS da região de Cidade Tiradentes e entorno, 2006.

mapa, os setores censitários da região de Cidade Tiradentes e entorno foram classificados em três grupos: baixa, média e alta vulnerabilidade social. Em seguida, foram selecionados apenas os setores de alta vulnerabilidade social.

Posteriormente, operacionalizou-se o conceito de vulnerabilidade ambiental, por meio da construção e análise de indicadores ambientais, relativos à proximidade de cursos d'água e à cobertura de esgoto. Assim, foram definidos dois tipos de área: as de baixa vulnerabilidade ambiental, que correspondem aos setores censitários com mais de $50 \%$ dos seus domicílios com cobertura da rede de esgoto e localizados a mais de 50 metros de cursos d'água; e as de alta vulnerabilidade ambiental, que englobam os setores com menos de $50 \%$ dos seus domicílios com cobertura da rede de esgoto e/ou localizados a menos de 50 metros de cursos d'água. Assim, os setores de alta vulnerabilidade ambiental são aqueles com baixa cobertura de esgoto e/ ou localizados muito próximos de cursos d'água (ALVES, 2006).

Portanto, na metodologia desenvolvida para o presente estudo, foi realizada a integração de dados socioeconômicos, demográficos e ambientais, por meio de metodologias de sensoriamento remoto, geoprocessamento e indicadores socioambientais, para análise das inter-relações entre os processos de expansão urbana recente e as situações de vulnerabilidade socioambiental, em nível intraurbano. ${ }^{13}$

\footnotetext{
${ }^{13}$ Cabe destacar que este trabalho faz parte de um conjunto de metodologias de integração de dados sociodemográficos e ambientais para análise da vulnerabilidade socioambiental em áreas urbanas, que foram desenvolvidas em estudos recentes (ALVES, 2009).
} 


\section{Análise dos indicadores socioeconômicos e demográficos para as duas categorias de vulnerabilidade [socio]ambiental}

Nesta parte do trabalho, analisam-se os setores censitários de alta vulnerabilidade social da região de Cidade Tiradentes e entorno (selecionados do Mapa da vulnerabilidade social), de acordo com as duas categorias de vulnerabilidade ambiental apresentadas na metodologia, as quais foram construídas com base em indicadores de risco e degradação ambiental, mais precisamente da combinação das variáveis relativas a proximidade de cursos d'água e cobertura de esgoto. Portanto, neste trabaIho, analisa-se a vulnerabilidade ambiental apenas para os setores censitários de alta vulnerabilidade social.

A região de estudo (Distrito de Cidade Tiradentes e entorno) possuía uma população de 266 mil pessoas em 2000, das quais 149 mil residiam em áreas (setores censitários) de alta vulnerabilidade social, o que correspondia a $56 \%$ da população da região. Entre os moradores em áreas de alta vulnerabilidade social, 68,8\% (102,4 mil pessoas) encontravam-se em áreas com baixa vulnerabilidade ambiental e 31,2\% (46,5 mil pessoas) naquelas com alta vulnerabilidade ambiental (Tabela 1 e Mapa 3).

A seguir, realiza-se a comparação entre os indicadores socioeconômicos e demográficos desses dois grupos de vulnerabilidade ambiental, para observar as expressivas diferenças entre eles.

Inicialmente, compara-se o acesso a serviços públicos, no caso, às condições de saneamento básico, para os dois grupos de vulnerabilidade ambiental. Como mostram os indicadores da Tabela 1, as diferenças entre os dois grupos são significativas em relação às coberturas da rede de abastecimento de água e da coleta de lixo. Assim, enquanto no grupo de baixa vulnerabilidade ambiental o acesso à rede de água e à coleta de lixo é quase universal, nas áreas de alta vulnerabilidade ambiental os acessos a estes dois serviços atingem porcentagens

TABELA 1

Indicadores socioeconômicos e demográficos, por grupo de vulnerabilidade ambiental Distrito de Cidade Tiradentes e entorno - 2000

\begin{tabular}{|c|c|c|}
\hline Indicadores & Baixa vulnerabilidade ambiental & Alta vulnerabilidade ambiental \\
\hline Número de domicílios & 26.128 & 11.720 \\
\hline População residente & 102.456 & 46.532 \\
\hline Distribuição dos domicílios (\%) & 69,03 & 30,97 \\
\hline Distribuição da população (\%) & 68,77 & 31,23 \\
\hline Domicílios com rede de água (\%) & 98,84 & 87,20 \\
\hline Domicílios com rede de esgoto (\%) & 93,25 & 40,74 \\
\hline Domicílios com coleta de lixo (\%) & 98,79 & 90,06 \\
\hline $\begin{array}{l}\text { Chefes de domicílio com escolaridade de } 0 \text { a } \\
3 \text { anos de estudo (\%) }\end{array}$ & 23,56 & 31,18 \\
\hline Número médio de anos estudo & 5,70 & 5,02 \\
\hline Chefes de domicílio analfabetos (\%) & 12,16 & 15,05 \\
\hline $\begin{array}{l}\text { Chefes de domicílio com renda de } 0 \text { a } 3 \\
\text { salários mínimos (\%) }\end{array}$ & 59,98 & 67,89 \\
\hline $\begin{array}{l}\text { Renda média dos chefes de domicílio } \\
\text { (em reais) }\end{array}$ & 462,92 & 395,86 \\
\hline $\begin{array}{l}\text { Renda média dos chefes de domicílio } \\
\text { (em salários mínimos de 2000) }\end{array}$ & 3,07 & 2,62 \\
\hline População de 0 a 4 anos (\%) & 11,45 & 13,31 \\
\hline População de 0 a 19 anos (\%) & 44,79 & 46,43 \\
\hline
\end{tabular}

Fonte: IBGE. Censo Demográfico de 2000; CEM-Cebrap; SAS-PMSP. Mapa da vulnerabilidade social da população da cidade de São Paulo; CEM-Cebrap. Cartografia digital da rede hidrográfica de São Paulo. 
MAPA 3

Classificação dos setores censitários de alta vulnerabilidade social em dois grupos de vulnerabilidade ambiental Distrito de Cidade Tiradentes e entorno - 2000

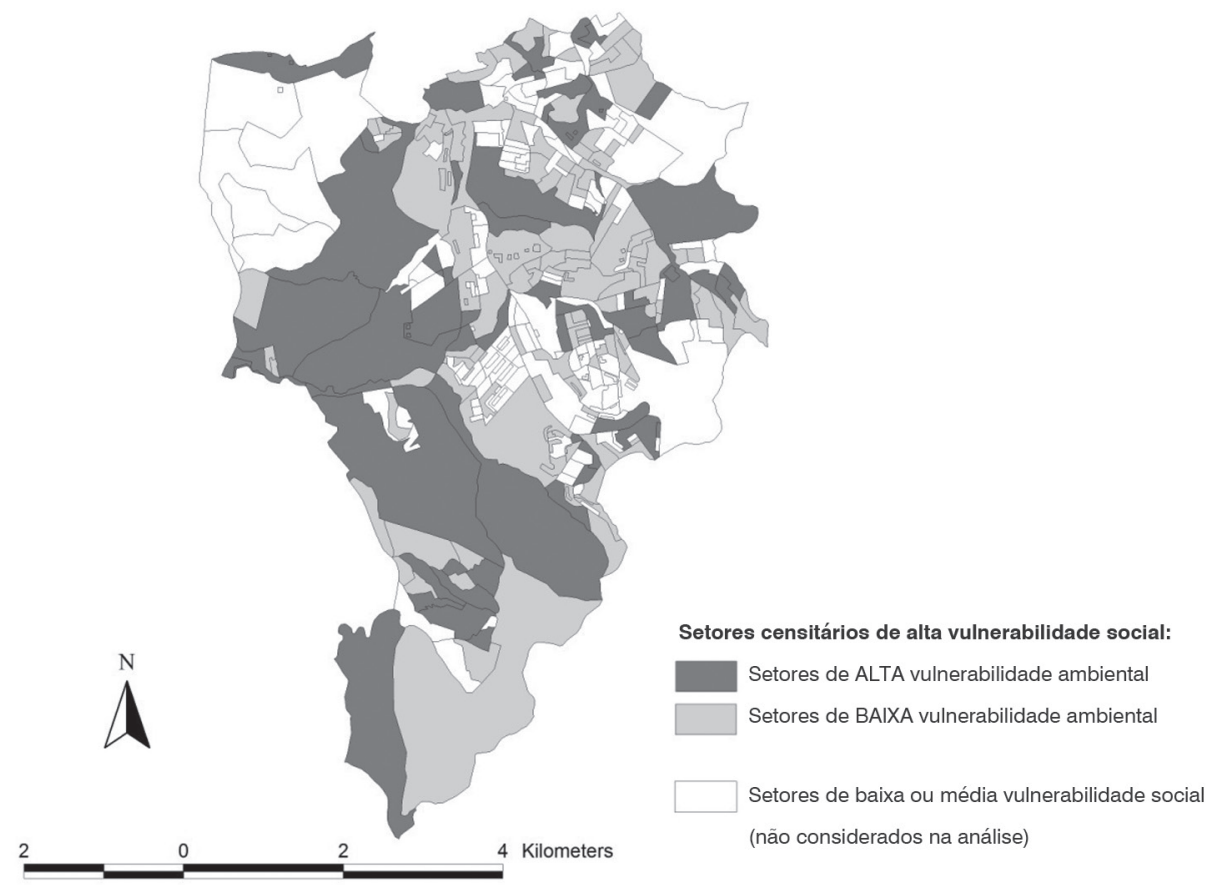

Fonte: IBGE. Malha digital dos setores censitários do Censo 2000 do município de São Paulo; CEM-Cebrap; SAS-PMSP. Mapa da vulnerabilidade social da população da cidade de São Paulo; CEM-Cebrap. Cartografia digital da rede hidrográfica de São Paulo.

médias bem menores, com $87,2 \%$ para rede de água e $90,1 \%$ para coleta de lixo.

Já em relação à cobertura de esgoto, as diferenças entre os dois grupos são extraordinárias. Enquanto nas áreas de baixa vulnerabilidade ambiental $93,3 \%$ dos domicílios estão ligados à rede de esgoto, no grupo de alta vulnerabilidade ambiental este percentual é de meros $40,7 \%$, o que revela a total ausência de cobertura da rede de esgoto na maioria dos domicílios deste grupo.

As diferenças nos indicadores de escolaridade e de renda também são bastante expressivas entre os dois grupos de vulnerabilidade ambiental. Nas áreas classificadas na categoria de baixa vulnerabilidade ambiental (com alta cobertura de esgoto e fora da mar- gem de curso d'água), $23,6 \%$ dos chefes de domicílio possuem baixa escolaridade (até três anos de estudo), percentual que chega a $31,2 \%$ nas áreas de alta vulnerabilidade ambiental (com baixa cobertura de esgoto e/ou à margem de curso d'água) (Tabela 1).

Nos indicadores de renda, também se observa considerável variação entre os dois grupos de vulnerabilidade ambiental. A concentração de chefes de domicílio com baixa renda (que recebem até três salários mínimos, incluindo-se os sem renda) é significativamente maior nas áreas de alta vulnerabilidade ambiental $(67,9 \%)$ do que naquelas com baixa vulnerabilidade ambiental $(60 \%)$ (Tabela 1). ${ }^{14}$

Com relação à estrutura etária da população, as diferenças entre os dois grupos

\footnotetext{
14 Estas diferenças se refletem numa significativa variação da renda média do responsável pelo domicílio entre as duas categorias de vulnerabilidade ambiental. Enquanto nos setores censitários de baixa vulnerabilidade ambiental a renda média mensal do chefe de domicílio chega a 463 reais (3,1 salários mínimos em 2000), nos setores de alta vulnerabilidade ambiental a renda média é de apenas 396 reais (2,6 salários mínimos).
} 
de vulnerabilidade ambiental também são significativas. Nas áreas de alta vulnerabilidade ambiental, as crianças de zero a quatro anos de idade ${ }^{15}$ representam $13,3 \%$ da população, enquanto naquelas de baixa vulnerabilidade ambiental correspondem a $11,5 \% .{ }^{16}$

Em resumo, os resultados mostram que as áreas (setores censitários) com alta vulnerabilidade ambiental possuem condições socioeconômicas significativamente piores, além de maior concentração de crianças e jovens, do que aquelas com baixa vulnerabilidade ambiental.

Uma explicação para esta elevada concentração de problemas e riscos sociais e ambientais, nas áreas de alta vulnerabilidade ambiental, está ligada ao fato de que estas, muitas vezes, são as únicas localidades acessíveis à população de mais baixa renda, pois são muito desvalorizadas no mercado de terras por serem pouco propícias à ocupação, devido às características de risco e falta de infraestrutura urbana. Outra possível explicação é a de que estes locais correspondem a áreas não edificantes, isto é, consideradas impróprias, pelas legislações urbanística e ambiental, para ocupação urbana, seja porque oferecem risco ambiental, seja porque são áreas de preservação permanente. Neste caso, na maioria das vezes, são áreas (públicas ou privadas) invadidas, em geral por assentamentos precários, que se configuram como áreas de favela.

\section{Análise dos tipos de uso e cobertura do solo e da expansão urbana para as duas categorias de vulnerabilidade [socio] ambiental}

A seguir, realiza-se uma análise comparativa entre as duas categorias de vulnerabilidade ambiental (descritas na metodologia e no item anterior), em relação aos tipos de uso e cobertura do solo e aos processos de expansão urbana, a partir da classificação de duas imagens de satélite IKONOS (de
2000 e 2006) da região da Cidade Tiradentes e entorno.

Os resultados revelam que, nas áreas (setores censitários) de baixa vulnerabilidade ambiental, predominam assentamentos formalizados e legalizados, como conjuntos habitacionais e zonas residenciais consolidadas. Já nas áreas (setores censitários) de alta vulnerabilidade ambiental, são mais expressivos os assentamentos precários e informais, tais como favelas e loteamentos irregulares (Tabelas 2, 3 e 4).

A classificação da imagem de satélite IKONOS de 2000 mostra que, no conjunto de setores censitários de baixa vulnerabilidade ambiental, $67 \%$ da malha urbana correspondia a assentamentos não precários (ou formalizados), sendo 19,4\% de conjuntos habitacionais e $47,6 \%$ de zonas residenciais consolidadas. Nessas áreas de baixa vulnerabilidade ambiental, os assentamentos precários englobavam apenas $19,2 \%$ da mancha urbana, sendo $14,2 \%$ de loteamentos irregulares e $5 \%$ de favelas.

Já no conjunto de setores censitários de alta vulnerabilidade ambiental, a proporção da mancha urbana ocupada por assentamentos precários chegava a expressivos $44 \%$, dos quais $30 \%$ eram loteamentos irregulares e 13,9\% favelas. Nessas áreas, os assentamentos não precários (ou formalizados) correspondiam a apenas $38,6 \%$ da mancha urbana, sendo $11,6 \%$ de conjuntos habitacionais e $27,1 \%$ de zonas residenciais consolidadas (Tabela 2).

Também cabe destacar que os assentamentos precários presentes no grupo de alta vulnerabilidade ambiental ocupavam uma área quase duas vezes maior do que no grupo de baixa vulnerabilidade ambiental, com respectivamente 197 e 106 hectares.

Em resumo, a classificação da imagem de satélite de 2000 revela que tanto a proporção como a extensão territorial de assentamentos precários nas áreas de alta vulnerabilidade ambiental possuem dimen-

\footnotetext{
15 Como as crianças de zero a quatro anos são as mais vulneráveis a doenças de veiculação hídrica, este resultado reforça a situação de vulnerabilidade socioambiental das áreas à beira dos cursos d'água e com baixa cobertura de esgoto.

16 Já o percentual de crianças e jovens de zero a 19 anos varia de $44,8 \%$ nas áreas de baixa vulnerabilidade ambiental a $46,4 \%$ naquelas de alta vulnerabilidade ambiental.
} 
são duas vezes maior do que naquelas de baixa vulnerabilidade ambiental. Estes dados reforçam a hipótese de sobreposição entre vulnerabilidades sociais e ambientais, com concentração e cumulatividade de problemas e riscos sociais e ambientais em determinadas áreas, espalhadas pelas periferias da metrópole de São Paulo.
Entre 2000 e 2006, ocorreu um processo bastante dinâmico de expansão urbana na região do distrito de Cidade Tiradentes e entorno, com a mancha urbana passando de 1.637 hectares, em 2000, para 1.886 hectares, em 2006, correspondendo a um crescimento de quase 250 hectares (ou $15,2 \%)$ nesse período.

TABELA 2

Uso e cobertura do solo, por grupo de vulnerabilidade ambienta Distrito de Cidade Tiradentes e entorno - 2000

\begin{tabular}{lccccc}
\hline \multirow{2}{*}{ Tipos de uso } & \multicolumn{2}{c}{ Baixa vulnerabilidade ambiental } & & \multicolumn{2}{c}{ Alta vulnerabilidade ambiental } \\
\cline { 2 - 3 } \cline { 5 - 6 } & Área (ha) & $\%$ & & Área (ha) & \% \\
\hline Conjunto habitacional & 108,14 & 19,38 & & 51,83 & 11,56 \\
Residencial consolidado & 265,79 & 47,64 & & 121,39 & 27,07 \\
Assentamentos não precários & $\mathbf{3 7 3 , 9 3}$ & $\mathbf{6 7 , 0 2}$ & & $\mathbf{1 7 3 , 2 2}$ & $\mathbf{3 8 , 6 3}$ \\
\hline Favela & 27,66 & 4,96 & & 62,27 & 13,88 \\
Loteamento irregular & 79,16 & 14,19 & & 134,97 & 30,10 \\
Assentamentos precários & $\mathbf{1 0 6 , 8 1}$ & $\mathbf{1 9 , 1 5}$ & & $\mathbf{1 9 7 , 2 3}$ & $\mathbf{4 3 , 9 8}$ \\
\hline Área urbanizada (1) & 557,92 & 100,00 & & 448,46 & 100,00
\end{tabular}

Fonte: Imagem de satélite IKONOS de 2000; IBGE. Censo Demográfico de 2000; CEM-Cebrap; SAS-PMSP. Mapa da vulnerabilidade social. CEM-Cebrap. Cartografia digital da rede hidrográfica de São Paulo.

(1) Inclui áreas industriais, comerciais e institucionais.

TABELA 3

Uso e cobertura do solo, por grupo de vulnerabilidade ambiental Distrito de Cidade Tiradentes e entorno - 2006

\begin{tabular}{lccccc}
\hline \multirow{2}{*}{ Tipos de uso } & \multicolumn{2}{c}{ Baixa vulnerabilidade ambiental } & & \multicolumn{2}{c}{ Alta vulnerabilidade ambiental } \\
\cline { 2 - 3 } \cline { 5 - 6 } & Área (ha) & $\%$ & & Área (ha) & $\%$ \\
\hline Conjunto habitacional & 138,29 & 22,17 & & 88,98 & 15,86 \\
Residencial consolidado & 309,23 & 49,58 & & 156,18 & 27,84 \\
Assentamentos não precários & $\mathbf{4 4 7 , 5 2}$ & $\mathbf{7 1 , 7 6}$ & & $\mathbf{2 4 5 , 1 6}$ & $\mathbf{4 3 , 6 9}$ \\
\hline Favela & 27,64 & 4,43 & & 63,39 & 11,30 \\
Loteamento irregular & 47,93 & 7,69 & & 160,80 & 28,66 \\
Assentamentos precários & $\mathbf{7 5 , 5 7}$ & $\mathbf{1 2 , 1 2}$ & & $\mathbf{2 2 4 , 1 9}$ & $\mathbf{3 9 , 9 6}$ \\
\hline Área urbanizada (1) & 623,67 & 100,00 & & 561,08 & 100,00 \\
\hline
\end{tabular}

Fonte: Imagem de satélite IKONOS de 2006; IBGE. Censo Demográfico de 2000; CEM-Cebrap; SAS-PMSP. Mapa da vulnerabilidade social. CEM-Cebrap. Cartografia digital da rede hidrográfica de São Paulo.

(1) Inclui áreas industriais, comerciais e institucionais.

TABELA 4

Evolução no uso e cobertura do solo e expansão urbana, por grupo de vulnerabilidade ambiental Distrito de Cidade Tiradentes e entorno - 2000-2006

Em porcentagem

\begin{tabular}{lcc}
\hline Tipos de uso & $\begin{array}{c}\text { Baixa vulnerabilidade } \\
\text { ambiental }\end{array}$ & $\begin{array}{c}\text { Alta vulnerabilidade } \\
\text { ambiental }\end{array}$ \\
\hline Crescimento de assentamentos não precários & 19,68 & 41,53 \\
Crescimento de assentamentos precários & $-29,25$ & 13,67 \\
Crescimento da área urbanizada (1) & 11,79 & 25,11
\end{tabular}

Fontes: Imagens de satélite IKONOS de 2000 e 2006; IBGE. Censo Demográfico de 2000; CEM-Cebrap; SAS-PMSP. Mapa da vulnerabilidade social. CEM-Cebrap. Cartografia digital da rede hidrográfica de São Paulo.

(1) Inclui áreas industriais, comerciais e institucionais. 
Porém, comparando-se os dois grupos de vulnerabilidade ambiental, verificase que as áreas de alta vulnerabilidade ambiental tiveram uma expansão urbana muito maior do que aquelas de baixa vulnerabilidade ambiental, tanto em números absolutos como relativos. Assim, no período 2000-2006, enquanto no grupo de baixa vulnerabilidade ambiental a mancha urbana aumentou 66 hectares $(11,8 \%)$, no de alta vulnerabilidade ambiental, esse crescimento correspondeu a 113 hectares $(25,1 \%)$, ou seja, mais de $1 / 4$ da mancha urbana existente em 2000.

Outra diferença marcante entre os dois grupos diz respeito aos tipos de uso do solo que mais cresceram no período 2000-2006. No de baixa vulnerabilidade ambiental, a área ocupada por assentamentos não precários (ou formalizados) cresceu 19,7\% (74 ha), enquanto aquela ocupada por assentamentos precários diminuiu 29,3\% (31 ha). Esta redução significa que houve uma mudança para outros tipos de uso do solo, principalmente de loteamentos irregulares para zonas residenciais consolidadas, por meio da consolidação e regularização desses loteamentos (Tabela 4).

No grupo de alta vulnerabilidade ambiental, a área ocupada por assentamentos não precários (ou formalizados) aumentou em 72 ha, valor muito próximo ao do grupo de baixa vulnerabilidade ambiental (74 ha). Já em termos relativos, este crescimento foi bastante expressivo $(41,5 \%)$, o que é explicado pela pequena extensão territorial ocupada por assentamentos formalizados no grupo de alta vulnerabilidade ambiental em 2000. ${ }^{17}$

Porém, para a problemática abordada neste artigo, o que chama mais atenção é o significativo crescimento da área ocupada por assentamentos precários no grupo de alta vulnerabilidade ambiental, que passou de 197 hectares, em 2000, para 224 hectares, em 2006, correspondendo a um crescimento de 27 hectares (ou 13,7\%) nesse período. Tal expansão contrasta com a forte redução da área ocupada por assentamentos precários no grupo de baixa vulnerabilidade ambiental (Tabelas 2, 3 e 4).

Assim, verifica-se que ainda está havendo crescimento significativo de assentamentos precários (tais como loteamentos irregulares e favelas) nas áreas de alta vulnerabilidade ambiental da região de $\mathrm{Ci}$ dade Tiradentes e entorno. Este processo provavelmente também está ocorrendo em outras regiões hiperperiféricas e periurbanas da metrópole de São Paulo, gerando novas situações de vulnerabilidade socioambiental, uma vez que estas áreas se caracterizam pela forte presença de situações de risco e degradação ambiental, particularmente ausência de saneamento básico e proximidade de cursos d'água.

No entanto, no caso da região de Cidade Tiradentes e entorno, também é preciso destacar a ocorrência simultânea de crescimento de assentamentos formalizados e implantação de grandes conjuntos habitacionais. Porém, cabe investigar se este processo de crescimento de assentamentos mais formalizados é específico da região de Cidade Tiradentes, que concentra grande parte dos conjuntos habitacionais de São Paulo, ou se também está ocorrendo em outras áreas periféricas e periurbanas da metrópole de São Paulo.

Por fim, é importante destacar que, como resultado dos processos de expansão urbana ocorridos no período 2000-2006, os dois grupos de vulnerabilidade ambiental da região de Cidade Tiradentes e entorno ficaram ainda mais distintos em relação à distribuição dos tipos de uso do solo urbano. Assim, em 2006, as áreas urbanizadas do grupo de baixa vulnerabilidade ambiental possuíam $71,8 \%$ de assentamentos formalizados e apenas $12,1 \%$ de assentamentos precários. Já no grupo de alta vulnerabilidade ambiental, a proporção de assentamentos formalizados chegava a $43,7 \%$ das áreas urbanizadas em 2006, mas a proporção de assentamentos precários ainda era muito elevada, com 39,9\% (Tabela 3).

\footnotetext{
17 Mesmo com todo esse crescimento no período 2000-2006, a área ocupada por assentamentos formalizados no grupo de alta vulnerabilidade ambiental, em 2006, ainda corresponde a cerca de metade da área ocupada por este tipo de assentamento no grupo de baixa vulnerabilidade ambiental, com respectivamente 245 e 448 hectares (Tabela 3).
} 


\section{Discussão dos resultados e considerações finais}

No presente artigo, procurou-se operacionalizar o conceito de vulnerabilidade socioambiental, por meio de indicadores em escala intraurbana, para representar empiricamente os fenômenos de sobreposição espacial de riscos e vulnerabilidades sociais e ambientais, bem como suas relações com os processos de expansão urbana e periferização, em uma região hiperperiférica da metrópole de São Paulo.

Os resultados das análises mostram que as áreas urbanas da região de Cidade Tiradentes e entorno, assim como de grande parte das regiões hiperperiféricas da Região Metropolitana de São Paulo, continuam crescendo muito rapidamente. Estas áreas são ocupadas por população de baixa renda, como mostram os dados do Censo 2000, e apresentam elevado número de áreas de ocupação precária e informal em termos de uso do solo, como pode ser inferido das imagens de satélite de 2000 e 2006.

Além disso, os resultados também revelam a existência de grandes sobreposições entre vulnerabilidades sociais e ambientais, com forte concentração de problemas e riscos sociais e ambientais em determinadas áreas, como é o caso dos setores censitários de alta vulnerabilidade social e ambiental da região de Cidade Tiradentes e entorno. Como visto, estas áreas de alta vulnerabilidade socioambiental apresentam elevados níveis de irregularidade no uso do solo, com forte presença (em termos absolutos e relativos) de assentamentos precários, como favelas e loteamentos irregulares, além de condições socioeconômicas extremamente desfavoráveis, com baixíssimos níveis de renda, escolaridade e saneamento. Desse modo, a crescente sobreposição e o acúmulo de problemas e riscos sociais e ambientais fazem com que situações de pobreza e vulnerabilidade social sejam agravadas pela exposição a riscos e degradação ambiental, tais como enchentes, deslizamentos de terra, poluição, contato com doenças de veiculação hídrica, etc.

Em síntese, os resultados das análises comparativas entre as duas categorias de vulnerabilidade ambiental (no âmbito dos setores de alta vulnerabilidade social) da região de Cidade Tiradentes e entorno, em relação aos tipos de uso e cobertura do solo e aos processos de expansão urbana, mostram que:

- as diferenças no uso do solo urbano entre os dois grupos de vulnerabilidade ambiental são muito expressivas, com elevada proporção de assentamentos precários (favelas e loteamentos irregulares) nas áreas de alta vulnerabilidade ambiental e pequena proporção deste tipo de assentamento naquelas de baixa vulnerabilidade ambiental;

- a mancha urbana das áreas de alta vulnerabilidade ambiental teve um crescimento substancialmente maior do que a daquelas de baixa vulnerabilidade ambiental, no período 2000-2006;

- nas áreas de alta vulnerabilidade ambiental, os assentamentos precários (favelas e loteamentos irregulares) cresceram de maneira significativa;

- além das diferenças no uso do solo urbano, as áreas com alta vulnerabilidade ambiental possuem condições socioeconômicas significativamente piores e estrutura etária mais jovem, o que revela a sobreposição de vulnerabilidades sociais e ambientais.

Portanto, estes resultados revelam uma expressiva associação entre os processos de expansão urbana e crescimento de assentamentos precários e as situações de vulnerabilidade socioambiental, na região hiperperiférica de Cidade Tiradentes e entorno.

Nesse sentido, os resultados obtidos pela metodologia utilizada credenciam este trabalho a estabelecer um diálogo e fazer contribuições relevantes para um conjunto de estudos sociodemográficos, urbanos e ambientais a respeito das relações entre os processos de expansão urbana/periferização e as sobreposições de riscos e vulnerabilidades sociais e ambientais na 
metrópole de São Paulo e em outras metrópoles do Brasil e do mundo (TORRES; COSTA, 2000; RIBEIRO, 2000; MEYER et al., 2004; TORRES; MARQUES, 2005; HOGAN; 2007; UNFPA, 2007; MARTINE et al., 2008).

Assim, uma das contribuições relevantes do presente trabalho para esta literatura está justamente na utilização de metodologias de geoprocessamento e sensoriamento remoto, que possibilitaram a identificação e caracterização (em termos quantitativos e espaciais) de situações de vulnerabilidade socioambiental em escala intraurbana, bem como a análise das suas relações com os processos de expansão urbana e periferização.

Além disso, a metodologia desenvolvida neste estudo representa uma contribuição para a detecção de áreas de alta vulnerabilidade socioambiental e expansão urbana recente, podendo ser estendida para outras regiões periféricas e periurbanas de São Paulo e de outras metrópoles do Brasil, fornecendo, assim, subsídios importantes para formulação de políticas públicas sociais e ambientais, relativas ao uso do solo e melhorias de habitação e saneamento, no sentido de regular e conter a expansão urbana descontrolada e de mitigar e enfrentar as situações de vulnerabilidade socioambiental.

Nesse sentido, cabe ressaltar que os estudos de população têm muito a contribuir com os estudos urbanos e ambientais, por meio do desenvolvimento de metodologias de integração de dados de diferentes tipos (demográficos, socioeconômicos, ambientais) e fontes (censos, imagens de satélite e cartografias ambientais), para análise das sobreposições entre riscos e vulnerabilidades sociais e ambientais. Em particular, acreditamos que o uso de metodologias de geoprocessamento e sensoriamento remoto é um dos caminhos mais frutíferos para ampliar este diálogo dos estudos de população com outras disciplinas que abordam os processos de urbanização e metropolização, principalmente o planejamento urbano e a geografia.

Neste contexto, reafirmamos que o presente artigo traz uma importante contribuição metodológica para os estudos de população, ao realizar a integração de fontes censitárias de dados sociodemográficos com cartografias ambientais (áreas de risco) e com imagens de satélite de alta resolução. Além disso, traz contribuições relevantes para os estudos urbanos e ambientais, por meio da identificação e caracterização de situações de vulnerabilidade socioambiental em escala intraurbana e das suas relações com os processos de periferização e expansão urbana.

Desse modo, o artigo insere-se na proposta do Grupo de Trabalho População, Espaço e Ambiente, da Associação Brasileira de Estudos Populacionais (Abep), de estabelecer um diálogo profícuo e permanente entre os estudos de população e os urbanos e ambientais.

Por fim, pode-se concluir que a alta concentração de problemas sociais e ambientais faz com que essas áreas hiperperiféricas e periurbanas da metrópole de São Paulo sejam bastante inadequadas para continuar recebendo novos assentamentos urbanos, particularmente os precários. Porém, é importante destacar que não se pode culpar as famílias e imigrantes de baixa renda que vão residir nessas áreas, gerando processos de expansão descontrolada da mancha urbana. $\mathrm{Na}$ verdade, eles são os primeiros a serem afetados pela degradação ambiental, não só pela exposição a riscos ambientais e vetores de doenças contagiosas, mas também porque seus domicílios são menos protegidos em termos de infraestrutura e condições de moradia, o que reforça o elevado grau de vulnerabilidade socioambiental destas famílias.

Assim, uma questão fundamental, suscitada pelos resultados deste trabalho, é como mudar o curso desses processos tão perversos e indesejáveis de expansão urbana descontrolada para áreas periféricas e periurbanas cada vez mais distantes. Apesar de não termos uma resposta fechada, uma das conclusões do trabalho é que só uma mudança significativa na dinâmica dos mercados imobiliário e de terras e a presença de políticas públicas relativas ao uso e ocupação do solo que utilizem informações atualizadas e pratiquem a fiscalização poderiam permitir um padrão de uso e ocupação 
do solo mais sustentável. Atualmente, as terras disponíveis nas porções mais centrais da metrópole não são ocupadas, devido tanto ao alto preço da terra nestas áreas quanto à falta de políticas públicas que pudessem

\section{Referências}

ALMEIDA, C. M.; CÂMARA, G.; MONTEIRO, A. M. V. (Orgs.). Geoinformação em urbanismo: cidade real $X$ cidade virtual. São Paulo: Oficina de Textos, 2007.

ALMEIDA, R.; D’ ANDREA, T.; DE LUCCA, D. Situações periféricas: etnografia comparada de pobrezas urbanas. Novos Estudos, São Paulo, Cebrap, n. 82, nov. 2008.

ALVES, H. P. F. Metodologias de integração de dados sociodemográficos e ambientais para análise da vulnerabilidade socioambiental em áreas urbanas no contexto das mudanças climáticas. In: HOGAN, D.; MARANDOLA JR., E. (Orgs.). População e mudança climática: dimensões humanas das mudanças ambientais globais. Campinas: Núcleo de Estudos de População - Nepo/ Unicamp; Brasília: UNFPA, 2009, p. 75-105.

. Desigualdade ambiental no município de São Paulo: análise da exposição diferenciada de grupos sociais a situações de risco ambiental através do uso de metodologias de geoprocessamento. Revista Brasileira de Estudos de População, São Paulo, v.24, n.2, p. 301-306, jul./dez. 2007.

. Vulnerabilidade socioambiental na metrópole paulistana: uma análise sociodemográfica das situações de sobreposição espacial de problemas e riscos sociais e ambientais. Revista Brasileira de Estudos de População, São Paulo, v. 23, n. 1, p. 4359, jan./jun. 2006.

ALVES, H. P. F.; TORRES, H. G. Vulnerabilidade socioambiental na cidade de São Paulo: uma análise de famílias e domicílios em situação de pobreza e risco ambiental. São Paulo em Perspectiva, São Paulo, Fundação Seade, v. 20, n. 1, p. 44-60, jan./mar. 2006.

ANDERSON, J. R.; HARDY, E. E.; ROACH, J. T. A land use classification system for redirecionar os novos assentamentos para muitas áreas já adensadas e dotadas de infraestrutura urbana, por meio de projetos habitacionais voltados para população de baixa renda.

use with remote-sensor data. Washington, D.C: Geological Survey, 1972.

BLASCHKE, T.; KUX, H. Sensoriamento Remoto e SIG Avançados. São Paulo: Oficina de textos, 2005.

BONDUKI, N.; ROLNIK, R. Periferia da Grande São Paulo: reprodução do espaço como expediente de reprodução da força de trabalho. In: MARICATO, E. (Org.). A produção capitalista da casa (e da cidade) do Brasil industrial. São Paulo: Alfa-Ômega, 1982.

CEM-CEBRAP; SAS-PMSP. Mapa da vulnerabilidade social da população da cidade de São Paulo. São Paulo: Sesc-SP, 2004.

DE SHERBININ, A.; SCHILLER, A.; PULSIPHER, A. The vulnerability of global cities to climate hazards. Environment \& Urbanization Journal, London, v. 19, n. 1, April 2007.

EMPLASA. Mapeamento de uso e ocupação do solo da RMSP - 2002. São Paulo, 2003.

HOGAN, D. (Org.). Dinâmica populacional e mudança ambiental: cenários para o desenvolvimento brasileiro. Campinas: Núcleo de Estudos de População - Nepo/ Unicamp, 2007.

JACOBI, P. R. Moradores e meio ambiente na cidade de São Paulo. Cadernos CEDEC, São Paulo, n. 43, 1995.

MARANDOLA JR., E.; HOGAN, D. J. Vulnerabilidade e riscos: entre geografia e demografia. Revista Brasileira de Estudos de População, São Paulo, v. 22, n. 1, p. 29-53, jan./jun. 2005.

MARCONDES, M. J. A. Cidade e natureza: proteção dos mananciais e exclusão social. São Paulo: Studio Nobel/Editora da USP/ Fapesp, 1999 (Coleção Diade Aberta). 
MARICATO, E. Metrópole na periferia do capitalismo: ilegalidade, desigualdade e violência. São Paulo: Hucitec, 1996.

Metrópole, legislação e desigualdade. Estudos Avançados, São Paulo, v. 17, n. 48, ago. 2003.

MARQUES, E.; TORRES, H. (Orgs.). São Paulo: segregação, pobreza e desigualdades sociais. São Paulo: Editora Senac, 2005.

MARTINE, G.; MCGRANAHAN, G.; MONTGOMERY, M.; CASTILLA-FERNANDEZ, R. (Orgs.). The new global frontier: urbanization, poverty and environment in the 21 st century. 1 ed. London: IIED/UNFPA and Earthscan Publications, 2008.

MEYER, R.; GROSTEIN, M.; BIDERMAN, C. São Paulo metrópole. São Paulo: Edusp, 2004.

OLIVEIRA, M. A.; ALVES, H. P. F. Expansão urbana e desmatamento nas áreas protegidas por legislação ambiental na Região Metropolitana de São Paulo. Cadernos IPPUR, Rio de Janeiro, Ano XXI, n. 2, p. 29-54, 2007.

PENG, J.; WANG, Y.; YE, M.; WU, J.; ZHANG, $Y$. Effects of land - use categorization on landscape metrics: a case study in urban landscape of Shenzhen, China. International Journal of Remote Sensing, v. 28, n. 21-22, p. 4.877-4.895, November 2007.

REIS, N. G.; TANAKA, M. S. Brasil: estudos sobre dispersão urbana. São Paulo: FAUUSP, 2007.

RIBEIRO, L. C. Q. (Org.). O futuro das metrópoles: desigualdades e governabilidade. Rio de Janeiro: Revan; Fase, 2000.

SMOLKA, M. Meio ambiente e estrutura urbana. In: MARTINE, G. (Org.). População, meio ambiente e desenvolvimento: verdades e contradições. Campinas: Editora da Unicamp, 1993.
TASCHNER, S. P. Degradação ambiental em favelas de São Paulo. In: TORRES, H.; COSTA, H. (Orgs.). População e meio ambiente: debates e desafios. São Paulo: Editora Senac, 2000.

TORRES, H. A fronteira paulistana. In: MARQUES, E.; TORRES, H. (Orgs.). São Paulo: segregação, pobreza e desigualdades sociais. São Paulo: Editora Senac, 2005, p. 101-119.

A demografia do risco ambiental. In: TORRES, H.; COSTA, H. (Orgs.). População e meio ambiente: debates e desafios. São Paulo: Editora Senac, 2000, p. 53-73.

TORRES, H.; COSTA, H. (Orgs.). População e meio ambiente: debates e desafios. São Paulo: Editora Senac, 2000, p. 53-73.

TORRES, H. G.; ALVES, H. P. F.; OLIVEIRA, M. A. São Paulo peri-urban dynamics: some social causes and environmental consequences. Environment \& Urbanization Journal, London, v. 19, n. 1, p. 207-223, April 2007a.

Expansão urbana, mercado imobiliário e degradação ambiental em São Paulo. In: HOGAN, D. (Org.). Dinâmica populacional e mudança ambiental: cenários para o desenvolvimento brasileiro. Campinas: Núcleo de Estudos de População - Nepo/Unicamp, 2007b.

TORRES, H.; MARQUES, E. Reflexões sobre a hiperperiferia: novas e velhas faces da pobreza no entorno metropolitano. Revista Brasileira de Estudos Urbanos e Regionais, n. 4, p. 49-70, 2001.

UNFPA. Situação da população mundial 2007: desencadeando o potencial do crescimento urbano. Nova York: Fundo de População das Nações Unidas, 2007. 


\section{Resumén}

Dinámicas de urbanización en la hiperperiferia de la metrópoli de San Pablo: análisis de los procesos de expansión urbana y de las situaciones de vulnerabilidad socioambiental en escala intraurbana

El objetivo del trabajo es realizar un análisis, en escala intraurbana, de las interrelaciones entre los procesos de expansión urbana y las situaciones de vulnerabilidad socioambiental, en una región hiperperiférica de la metrópoli de San Pablo, para el período 2000 a 2006. La referida región abarca el distrito de Ciudad Tiradentes y su entorno, en el extremo este del municipio de San Pablo. La metodología general del estudio incluye el mapeo del uso del suelo y de las áreas de expansión urbana, por medio de imágenes de satélite, así como la identificación y caracterización de situaciones (áreas) de vulnerabilidad socioambiental, por la construcción y análisis de indicadores socioambientais a nivel de los sectores censitarios del Censo 2000 del IBGE, integrando datos socioeconómicos, demográficos y ambientales. Los resultados revelan una expresiva asociación entre los procesos de expansión urbana y crecimiento de asentamientos precarios y las situaciones de vulnerabilidad socioambiental, en la región hiperperiférica de Ciudad Tiradentes y entorno. Además, se observa la existencia de grandes superposiciones entre vulnerabilidades sociales y ambientales, con fuerte concentración de problemas y riesgos sociales y ambientales en determinadas áreas, como es el caso de los sectores censitarios de alta vulnerabilidad socioambiental de la región de la Ciudad de Tiradentes y su entorno. Estas áreas presentan altos niveles de irregularidad en el uso del suelo, con fuerte presencia de asentamientos precarios como "favelas" y loteos irregulares, además de condiciones socioeconómicas extremadamente desfavorables, con bajos niveles de ingreso, escolaridad y saneamiento.

Palabras-clave: Expansión urbana. Vulnerabilidad socioambiental. Hiperperiferia. Metrópoli de San Pablo. Indicadores socioambientales. Geoprocesamiento. Monitoreo remoto.

\section{Abstract \\ Dynamics of urbanization in the hyperperiphery of the São Paulo Metropolitan Region: analysis of the processes of urban expansion and the situations of socioenvironmental vulnerability on an intraurban scale}

The objective of this article is to analyze, on an intraurban scale, the interrelations among processes of urban expansion and situations of socioenvironmental vulnerability in a hyperperipheral region of the São Paulo Metropolitan Region in recent years (2000 to 2006). This geographical region includes the district of Cidade Tiradentes and its surrounding area, located at the extreme eastern side of the municipality of São Paulo. The overall methodology of the study involves the mapping of the use of the soil and of the areas of urban expansion, using satellite images, as well as the identification and characterization of situations (areas) of socioenvironmental vulnerability. To this end, socioenvironmental indicators are constructed and analyzed based on census sectors from the Federal Census of 2000 , including socioeconomic, demographic and environmental data. The results show a strong correlation between the processes of urban expansion and growth of substandard settlements and situations of socioenvironmental vulnerability in the hyperperipheral region of Cidade Tiradentes and its surrounding area. It was also seen that there are broad overlappings between social and environmental vulnerabilities, with strong concentration of social and environmental problems and risks in certain areas, as is the case of the census sectors of high socioenvironmental vulnerability in the Cidade Tiradentes region. These areas show irregularity in the use of the soil and widespread presence of substandard settlements such as shantytowns and irregular 
subdivision projects. There are also extremely critical socioeconomic conditions, with very low levels of income, formal education and sanitation.

Keywords: Urban expansion. Socioenvironmental vulnerability. Hyperperiphery. São Paulo Metropolitan Region. Socioenvironmental indicators. Geoprocessing. Remote sensing.

Enviado para publicação em 03/11/2009

Aceito para publicação em 12/02/2010 